\title{
Depletion of 26S Proteasomes in Mouse Brain Neurons Causes Neurodegeneration and Lewy-Like Inclusions Resembling Human Pale Bodies
}

\author{
Lynn Bedford, ${ }^{1}$ David Hay, ${ }^{1}$ Anny Devoy, ${ }^{1}$ Simon Paine, ${ }^{1}$ Des G. Powe, ${ }^{2}$ Rashmi Seth, ${ }^{2}$ Trevor Gray, ${ }^{2}$ Ian Topham, \\ Kevin Fone, ${ }^{1}$ Nooshin Rezvani, ${ }^{1}$ Maureen Mee, ${ }^{1}$ Tim Soane, ${ }^{1}$ Robert Layfield, ${ }^{1}$ Paul W. Sheppard, ${ }^{3}$ Ted Ebendal, ${ }^{4}$ \\ Dmitry Usoskin, ${ }^{5}$ James Lowe, ${ }^{2 \star}$ and R. John Mayer ${ }^{1 \star}$ \\ ${ }^{1}$ School of Biomedical Sciences and ${ }^{2}$ School of Molecular Medical Sciences, University of Nottingham Medical School, Queen's Medical Centre, Nottingham \\ NG7 2UH, United Kingdom, ${ }^{3}$ BIOMOL International L.P., Exeter EX2 8NL, United Kingdom, ${ }^{4}$ Department of Neuroscience, Uppsala University, \\ SE-751 23 Uppsala, Sweden, and 5Division of Molecular Neurobiology, Department of Medical Biochemistry and Biophysics, Karolinska Institute, SE-171 \\ 77 Stockholm, Sweden
}

Ubiquitin-positive intraneuronal inclusions are a consistent feature of the major human neurodegenerative diseases, suggesting that dysfunction of the ubiquitin proteasome system is central to disease etiology. Research using inhibitors of the $20 \mathrm{~S}$ proteasome to model Parkinson's disease is controversial. We report for the first time that specifically 26S proteasomal dysfunction is sufficient to trigger neurodegenerative disease. Here, we describe novel conditional genetic mouse models using the Cre/loxP system to spatially restrict inactivation of Psmc1 (Rpt2/S4) to neurons of either the substantia nigra or forebrain (e.g., cortex, hippocampus, and striatum). PSMC1 is an essential subunit of the 26S proteasome and Psmc1 conditional knock-out mice display 26S proteasome depletion in targeted neurons, in which the $20 \mathrm{~S}$ proteasome is not affected. Impairment of specifically ubiquitin-mediated protein degradation caused intraneuronal Lewy-like inclusions and extensive neurodegeneration in the nigrostriatal pathway and forebrain regions. Ubiquitin and $\alpha$-synuclein neuropathology was evident, similar to human Lewy bodies, but interestingly, inclusion bodies contained mitochondria. We support this observation by demonstrating mitochondria in an early form of Lewy body (pale body) from Parkinson's disease patients. The results directly confirm that $26 \mathrm{~S}$ dysfunction in neurons is involved in the pathology of neurodegenerative disease. The model demonstrates that $26 \mathrm{~S}$ proteasomes are necessary for normal neuronal homeostasis and that 20S proteasome activity is insufficient for neuronal survival. Finally, we are providing the first reproducible genetic platform for identifying new therapeutic targets to slow or prevent neurodegeneration.

Key words: neuronal death; neuropathology; genetics; transgenic; Parkinson's disease; dementia; proteolysis

\section{Introduction}

The ubiquitin proteasome system (UPS) is the major regulated protein degradation mechanism of the cell, involving covalent tagging of unwanted proteins with polyubiquitin chains as a signal for their degradation by the multiprotein $26 \mathrm{~S}$ proteasome complex. This ATP-dependent complex is composed of a $20 \mathrm{~S}$

Received May 16, 2008; revised June 10, 2008; accepted June 26, 2008.

This work was supported by The Wellcome Trust, Biotechnology and Biological Sciences Research Council, Alzheimer's Research Trust, Neuroscience Support Group at the Queen's Medical Centre, and the Parkinson's Disease Society. T.E. and D.U. were supported by the Swedish Research Council. We thank Dr. R. Kuhn for the CaMKIl $\alpha$-Cre mice. Denise Watson, Lianne Finnerty, Janet Palmer, Neil Hand, and Howard Coleman (School of Molecular Medical Sciences, University of Nottingham Medical School) provided valuable technical assistance. We thank Drs. C. Gordon and S. Thomson (Medical Research Council Human Genetics, Western General Hospital, Edinburgh, UK) for detailed discussions and assistance leading to the inactivation of Psmc 1 by the Cre/loxP system. The studies were performed with British Home Office Project License 40/2688.

*J.L. and R.J.M. contributed equally to this work as part of 20 years collaborating on ubiquitin and neurodegenerative disease.

Correspondence should be addressed to R. John Mayer at the above address. E-mail: john.mayer@nottingham.ac.uk.

D0I:10.1523/JNEUROSCI.2218-08.2008

Copyright $\odot 2008$ Society for Neuroscience $\quad$ 0270-6474/08/288189-10\$15.00/0 proteolytic core particle (CP), directly abutted by 195 regulatory particles (RPs) (Voges et al., 1999; Pickart and Cohen, 2004; Schmidt et al., 2005; Demartino and Gillette, 2007). The cylindrical 20S CP is four heptameric rings involving seven distinct $\alpha$ and $\beta$ subunits stacked in a $\alpha_{1-7}-\beta_{1-7}-\beta_{1-7}-\alpha_{1-7}$ arrangement. The $\mathrm{N}$-terminal tails of the outer $\alpha$ subunits restrict substrate entry into the 20S CP and the inner proteolytic $\beta$ subunits (Groll et al., 1997, 2000; Groll and Huber, 2003). Two multimeric arrangements make up the 19S RP, the base and the lid, which play roles essential for $26 \mathrm{~S}$ proteasome function. A recent study into the spatial organization of subunits in the base of the 19S RP revealed that Rpn1/S2 and Rpn2/S1, two large non-ATPase base subunits, as well as the characterized six homologous AAA-ATPases (Rpt1-6) are responsible for coassembly of the 19S RP with the outer $\alpha$-rings of the 20S CP (Rosenzweig et al., 2008). Rpn1 and Rpn2 form a stacked central unit, in which Rpn2 binds directly to the surface of the 20S CP, which is encircled by the six nonredundant AAA-ATPases forming a hexameric ring (Rubin et al., 1998; Rosenzweig et al., 2008). Rpt2 (PSMC1/S4) has a unique role during $26 \mathrm{~S}$ proteasome formation and activation, opening the 
entry pore gated by the $\alpha$ subunits of the 20S CP, enabling protein substrates to be translocated into the proteolytic channel for degradation (Köhler et al., 2001; Smith et al., 2005, 2007). Polyubiquitin chains are recognized by subunits associated with the base of the 19S RP (e.g., non-ATPases Rpn1/S2, Rpn10/S5a, and Rpn13/ ARM1 and ATPase Rpt5/S6a), ensuring selective degradation by the 26 S complex (Elsasser et al., 2002; Lam et al., 2002; Husnjak et al., 2008). The 19S RP also has components that deubiquitinate proteins before their degradation (e.g., Rpn11/S13) (Koulich et al., 2008).

The UPS is necessary for intracellular homeostasis, not only by controlling the levels of short-lived regulatory proteins, which are involved in the cell cycle, transcription, and DNA repair, but importantly by removing aberrant proteins (Glickman and Ciechanover, 2002; Welchman et al., 2005). UPS-regulated proteolysis is emerging as part of neurodevelopment, synaptic function, and plasticity and the survival of neurons (Yi and Ehlers, 2007). Despite the recent interest in this field, a role for the ubiquitin system in neuronal physiology was first highlighted in chronic neurodegenerative disease. We have known for two decades that neuropathological inclusions in the majority of neurodegenerative diseases consistently contain ubiquitinated proteins, suggesting impairment of the UPS (Lowe et al., 1988). Genetic evidence also links ubiquitin system dysfunction to these diseases. The parkin gene, which is mutated in autosomal recessive juvenile Parkinson's disease (PD), is a ubiquitin protein ligase (Giasson and Lee, 2001). A functional role for proteasome impairment in PD pathogenesis has been controversial because of conflicting experimental data using inhibitors of the 20S proteolytic core (McNaught et al., 2004; Kordower et al., 2006), but changes in the ubiquitin system are involved in Huntington's disease neuropathology (Bennett et al., 2007; Wang et al., 2008). Genetic disruption of cellular ubiquitin pools was recently shown to cause selective neurodegeneration within the hypothalamic arcuate nucleus (Ryu et al., 2008). Also, inactivation of macroautophagy, the lessselective bulk intracellular protein degradation mechanism, in mouse brain neurons leads to neurodegeneration with ubiquitin pathology, suggesting that proteolytic dysfunction contributes to the neuropathology of neurodegenerative disease (Hara et al., 2006; Komatsu et al., 2006).

Notwithstanding the consistent links between the UPS, neuronal inclusions, and neurodegeneration, direct evidence involving primary inhibition of ubiquitin-mediated protein degradation by the $26 \mathrm{~S}$ proteasome complex in neurons has still not been demonstrated. The aim of this work was to genetically disrupt specifically $26 \mathrm{~S}$ proteasome degradation in mouse neurons, leaving the $20 \mathrm{~S}$ proteolytic core complex, which is involved in ubiquitin-independent degradation, unaffected. Therefore, we generated a reproducible conditional knock-out mouse using the Cre/loxP method for an essential subunit of the 19S RP, PSMC1 (Rpt2/S4). Two Cre deletor mouse strains were used to spatially restrict inactivation of $P s m c 1$ to predominantly the forebrain or substantia nigra, expressing Cre recombinase either under the control of the calcium calmodulin-dependent protein kinase II $\alpha$ $(\mathrm{CaMKII \alpha})$ promoter or from the tyrosine hydroxylase $(\mathrm{TH})$ locus (Lindeberg et al., 2002, 2004), respectively. We show here that loss of PSMC1 leads to 26S proteasome depletion, which causes neurodegeneration and the formation of intraneuronal Lewylike inclusions resembling human pale bodies (PBs) in neurons of the nigrostriatal pathway and forebrain. Our findings are significant advances in the experimental support for a direct role of the UPS in the pathogenic mechanisms of neurodegenerative disease.

\section{Materials and Methods}

\section{Generation of floxed Psmcl mice}

Using homologous recombination, a loxP-flanked neomycin-thymidine kinase selection cassette and a loxP site were inserted into introns 1 and 3 , respectively, of the Psmc1 gene (Gene ID 19179) in mouse 129/Sv embryonic stem (ES) cells (supplemental Fig. 1A, available at www. jneurosci.org as supplemental material). The selection cassette was excised by transient expression of Cre recombinase in vitro. PCR amplification identified correctly targeted ES cell clones. Male chimeric mice were generated using aggregation (Tanaka et al., 2001) with CD1-derived morulae and bred with CD1 females to establish homozygous floxed Psmcl mice $\left(P s m c 1^{\mathrm{fl} / \mathrm{fl}}\right)$.

\section{Region-specific inactivation of Psmc1}

Forebrain-specific ablation of Psmcl was achieved by crossing $P s m c 1^{\mathrm{f} / \mathrm{fl}}$ mice with CaMKII $\alpha$-Cre mice (Lindeberg et al., 2002), generating $P s m c 1^{\mathrm{f} / \mathrm{wt}} ;$ CaMKII $\alpha-W t$ and Psmc1 ${ }^{\mathrm{f} / \mathrm{wt}} ;$ CaMKII $\alpha$-Cre mice. Female $P s m c 1^{\mathrm{fl} / \mathrm{wt}} ; C a M K I I \alpha-C r e$ mice were mated with $P s m c 1^{\mathrm{fl} / \mathrm{fl}}$ males to produce mice in which Psmcl was selectively inactivated in calcium calmodulin-dependent protein kinase II $\alpha$-expressing cells $\left(P_{s m c 1} 1^{\mathrm{f} / \mathrm{fl}}\right.$; $C a M K I I \alpha-C r e)$ and control mice $\left(P s m c 1^{\mathrm{fl} / \mathrm{fl}} ;\right.$ CaMKII $\alpha-W t$ or $P s m c 1^{\mathrm{fl} / \mathrm{wt}}$; $C a M K I I \alpha-W t)$. For catecholaminergic neurone-specific inactivation of $P s m c 1, P s m c 1^{\mathrm{fl} / \mathrm{fl}}$ mice were crossed with $T H^{\text {Cre }}$ mice (Lindeberg et al., 2004) generating $P s m c 1^{\mathrm{f} / \mathrm{wt}} ; T H^{\mathrm{Cre}}$ and $P s m c 1^{\mathrm{fl} / \mathrm{wt}} ; T H^{\mathrm{wt}}$ animals. Male $P s m c 1^{\mathrm{fl} / \mathrm{wt}} ; T H^{\mathrm{Cre}}$ mice were bred with $P s m c 1^{\mathrm{fl} / \mathrm{fl}}$ females to produce mice deficient in $P s m c 1$ specifically in tyrosine hydroxylase-expressing cells $\left(P s m c 1^{\mathrm{fl} / \mathrm{fl}} ; T H^{\mathrm{Cre}}\right.$ or $\left.P s m c 1^{\mathrm{fl} / \mathrm{ko}} ; T H^{\mathrm{Cre}}\right)$ and control mice $\left(P s m c 1^{\mathrm{fl} / \mathrm{fl}}\right.$; $T H^{\mathrm{wt}}$ or $\left.P s m c 1^{\mathrm{fl} / \mathrm{wt}} ; T H^{\mathrm{Cre}}\right)$.

\section{Genotyping}

PCR amplification of ear biopsy DNA was used for genotyping.

\section{Quantitative real-time $R T$-PCR}

Total RNA was extracted using a QIAGEN RNeasy Micro kit. RNA was eluted with RNase-free water and quantified using a Nanodrop. A total of 500 ng of DNase 1 (Promega)-treated RNA provided the substrate for cDNA synthesis using oligo-dT $\mathrm{T}_{18}$ and Invitrogen Superscript III Reverse Transcriptase according to manufacturers instructions. A total of $10 \mu \mathrm{l}$ of real-time RT-PCRs was run using Stratagene Brilliant SYBR Green QPCR Master Mix and a Stratagene Mx3005P QPCR System. Primers (100 nM) for Psmc1 and glyceraldehyde phosphate dehydrogenase $(G A P D H)$ were used. Analysis used Stratagene MxPro QPCR software, generating a standard curve from plasmid dilutions. Experimental samples were analyzed in triplicate, and gene expression was normalized to $G A P D H$ and expressed as a fold change of the controls.

\section{Sedimentation velocity analysis}

This was performed as described previously (Tanahashi et al., 2000).

\section{Western analysis}

Microdissected brain regions were homogenized on ice in $50 \mathrm{~mm}$ Tris, $\mathrm{pH} 7.4,175 \mathrm{~mm} \mathrm{NaCl}$, and $5 \mathrm{~mm}$ EDTA, and subjected to SDS-PAGE, and the separated proteins were transferred to nitrocellulose membrane. Incubation in the appropriate primary antibodies was for $1 \mathrm{~h}$ at room temperature [ubiquitin, 1:1000 (in-house), or synaptophysin, 1:1000 (Calbiochem)], and visualization used horseradish peroxidiseconjugated secondary antibodies (Sigma-Aldrich) and enhanced chemiluminescent substrate (Pierce). Protein analysis after adenoviral Cre recombinase treatment of mouse embryonic fibroblast cells was performed by recovering denatured protein from the cell lysate flowthrough during QIAGEN RNeasy Micro purification of total RNA as described in the handbook. Protein was subjected to SDS-PAGE as described above [PSMC1, 1:1000 (in-house), or actin, 1:1000 (Sigma-Aldrich)].

\section{Histology}

For light microscopy, mice were perfusion-fixed with $4 \%$ paraformaldehyde in $0.1 \mathrm{~m}$ phosphate buffer, $\mathrm{pH} 7.4$, and brains were embedded in paraffin wax and sectioned $(5 \mu \mathrm{m})$ according to standard protocols. General morphological examination used hematoxylin (Harris) and eosin staining. Immunostaining was performed as directed in Vector Laboratories M.O.M. immunodetection or Vectastain Elite rabbit IgG ABC 
kits. Antigen retrieval used microwave treatment in $0.01 \mathrm{M}$ citrate buffer containing $0.05 \%$ Tween 20 , pH 6, or 10 mM EDTA followed by formic acid treatment. Primary antibody incubation was for $1 \mathrm{~h}$ at room temperature: 1:2000 tyrosine hydroxylase (Sigma-Aldrich), 1:2000 ubiquitin (Dako), 1:4000 glial fibrillary acidic protein (GFAP) (Dako), 1:5 (Vector) or 1:10,000 (Dr. Diane Hanger, Institute of Psychiatry, King's College London, London, UK) $\alpha$-synuclein, 1:1000 p62 (BIOMOL), 1:5 $\gamma$-tubulin, 1:100 activated caspase-9 (Cell Signaling), 1:600 cytochrome oxidase IV (cox IV) (Cell Signaling), 1:50 p53 (Calbiochem), and 1:1000 PSMC1 (BIOMOL). Analyses used an Olympus BX51 microscope and camera. For electron microscopic analyses, 3.2\% paraformaldehyde, $0.2 \%$ glutaraldehyde, $1 \%$ sucrose, $3 \mathrm{mM} \mathrm{CaCl}_{2}$ in $0.1 \mathrm{~m}$ sodium cacodylate buffer was used. When cryosections were needed, brains were dissected and frozen in precooled isopentane over liquid nitrogen. For laser capture microdissection, cryostat sections $(10 \mu \mathrm{m})$ were cut onto PEN membrane slides (Carl Zeiss) and fixed in precooled acetone for 5 min. The sections were immunostained using $\mathrm{TH}$ as described previously. Immunopositive $\mathrm{TH}$ cells were microdissected and laser pressure catapulted into adhesive caps using a PALM microbeam Microdissector (Carl Zeiss). For thioflavin S staining, sections were stained in hematoxylin for $5 \mathrm{~min}$, followed by washing in water and then incubating in $1 \%$ thioflavin S for $10 \mathrm{~min}$. Sections were washed in 50\% ethanol and then water for 5 min each before mounting in Gel Mount (Sigma-Aldrich). Immunogold electron microscopy was performed by routine methods with $10 \mathrm{~nm}$ gold (Agar Scientific) as described previously (László et al., 1991).

\section{Behavioral analyses}

Open field. Each mouse was monitored for $5 \mathrm{~min}$ in an open-field arena $(350 \times 300 \times 300 \mathrm{~mm}$; three walls transparent, one wall and floor dark gray). Activity in the open field was recorded and quantitated by a computer-operated animal activity system.

Morris water maze. A hidden-platform test performed in an opaque pool at $\sim 25^{\circ} \mathrm{C}$. Over 3 consecutive days, three blocks of six trials lasting $120 \mathrm{~s}$ each from two compass points located on the pool (18 trials total) were carried out. The time taken to reach the platform (latency to escape) was recorded for each trial. The $120 \mathrm{~s}$ probe trial in which the platform was removed was on day 4 from a start position opposite the original platform location.

\section{Statistical analysis}

Data analysis used two-tailed unpaired Student's $t$ test with unequal variance. Statistical significance is indicated in the appropriate figure.

\section{Results}

Generation of neuron-specific $26 \mathrm{~S}$ proteasome-depleted mice To study the direct effect of impaired 26S-mediated degradation of ubiquitinated proteins in neurons, a key subunit of the 19S RP was genetically targeted, ATPase Psmc1 (Gene ID 19179) (Rubin et al., 1998; Köhler et al., 2001; Smith et al., 2007). As anticipated, $P s m c 1$ knock-out mice $\left(P s m c 1^{\text {ko/ko }}\right.$ ) were embryonic lethal (data not shown). Therefore, Psmc1 conditional knock-out mice $\left(P s m c 1^{\mathrm{fl} / \mathrm{fl}}\right)$ were generated (supplemental Fig. $1 A$, available at www.jneurosci.org as supplemental material). To spatially restrict ablation of $P s m c 1, P s m c 1^{\mathrm{fl} / \mathrm{fl}}$ mice were crossed with Cre deletor mouse strains, expressing Cre recombinase under the control of either the CaMKII $\alpha$ promoter $\left(P_{s m c 1}{ }^{\text {fl/fl }} ; C a M K I I \alpha-\right.$ Cre) or from the $T H$ locus $\left(P s m c 1^{\mathrm{fl} / \mathrm{fl}} ; T H^{\mathrm{Cre}}\right)$ (Lindeberg et al., 2002, 2004). The CaMKII $\alpha$ promoter directs expression to neurons predominantly in forebrain regions (Burgin et al., 1990; Mayford et al., 1996; Tsien et al., 1996). Expression is negligible during prenatal and perinatal development, and then dramatically upregulated during postnatal weeks 2 and 3, permitting normal CNS development before Cre-mediated recombination of $P s m c 1$ in postmitotic neurons. In $P s m c 1^{\mathrm{fl} / \mathrm{fl}} ; \mathrm{TH}^{\mathrm{Cre}}$ mice, $\mathrm{TH}$ is expressed from midgestation in midbrain dopaminergic neurons (Bayer et al., 1995).
Table 1. mRNA changes for selected 265 proteasomal, autophagic, and apoptotic genes after ablation of Psmc1

\begin{tabular}{|c|c|c|c|c|}
\hline \multirow[b]{2}{*}{ Subunit } & \multicolumn{4}{|c|}{ Increase (fold) } \\
\hline & Day 1 & Day 2 & Day 3 & Day 4 \\
\hline Psmc1 & $0.1^{* *}$ & - & - & - \\
\hline$\alpha 7$ & 1.4 & 1.1 & $3.6^{*}$ & 1.5 \\
\hline$\beta 5$ & 0.8 & 1.1 & $2.4^{* *}$ & 1.5 \\
\hline SUG1 & 0.8 & 1.4 & $2.6^{*}$ & 0.9 \\
\hline $\mathrm{POH} 1$ & 1 & 1.1 & $2.6^{* *}$ & $1.6^{* *}$ \\
\hline Atg7 & ND & ND & 1.7 & ND \\
\hline Atg8 & ND & ND & 0.8 & ND \\
\hline $\mathrm{BCl} 2$ & ND & ND & $0.2^{* *}$ & ND \\
\hline
\end{tabular}

$P_{\text {smc }} 7^{f / w t}$ (control) and $P_{s m c} f^{f / k o}$ (mutant) MEFs were transduced on day 0 with adenoviral Cre recombinase (multiplicity of infection, 850 ; Vector Laboratories), and $\mathrm{mRNA}$ analysis was performed by real-time RT-PCR over $4 \mathrm{~d}$. Representative proteasomal subunits are $\alpha 7$ and chymotryptic $\beta 5$ of the 205 core complex, and SUG1/p45 ATPase and POH1 from the base and lid of the 195 regulatory particle, respectively. Atg7, Atg8, and BCI2 represent changes in macroautophagy and apoptotic mechanisms, respectively. Gene expression was normalized to GAPDH and expressed as a fold change compared with the controls. - , No expression; ND, not done.

${ }^{* *} p<0.01,{ }^{*} p<0.05$ by two-tailed Student's $t$ test.

Cre-mediated recombination of $P s m c 1^{\mathrm{fl} / \mathrm{fl}}$ in the mouse brain was confirmed by PCR analysis of $P s m c 1^{\mathrm{fl} / \mathrm{fl}} ; C a M K I I \alpha-C r e$ and $P s m c 1^{\mathrm{fl} / \mathrm{fl}} ; T H^{\mathrm{Cre}}$ mice (supplemental Fig. $1 B, C$, available at www.jneurosci.org as supplemental material) (data not shown). Because Cre deletor mice only target specific neurons, the mixed cell population of the brain proved unsuitable for analysis of Psmcl mRNA expression. Therefore, we captured Psmc1targeted neurons using laser capture microdissection (e.g., THexpressing neurons from the substantia nigra or adrenal medulla of $P s m c 1^{\mathrm{ll} / \mathrm{fl}} ; T H^{\mathrm{Cre}}$ mice). No cycle threshold value (Ct) was obtained for Psmc1 expression by real-time RT-PCR at 3 weeks of age. Immunostaining of cortex sections from 6-week-old Psmcl $^{\mathrm{fl} / \mathrm{fl}}$;CaMKII $\alpha$-Cre and control mice showed deletion of PSMC1 in cortical neurons of $P s m c 1^{\mathrm{fl} / \mathrm{fl}} ; C a M K I I \alpha$-Cre mice. In addition, sequential sections of 1 week substantia nigra were stained with anti-TH and anti-PSMC1 antibodies, demonstrating the loss of PSMC1 in residual TH+ cells of $P s m c 1^{\mathrm{fl} / \mathrm{fl}} ; T H^{\mathrm{Cre}}$ mice (supplemental Fig. $1 D$, available at www.jneurosci.org as supplemental material).

To substantiate gene expression changes in a homogenous cell population, we established an in vitro model of Psmc1 ablation using mouse embryonic fibroblasts (MEFs) derived from mating $P s m c 1^{\mathrm{ko} / \mathrm{wt}}$ and $P s m c 1^{\mathrm{fl} / \mathrm{fl}}$ mice. $P s m c 1^{f l / w t}$ (control) and $P s m c 1^{f l / k o}$ (mutant) MEFs were transduced with adenoviral Cre recombinase green fluorescent protein (GFP) to inactivate the floxed Psmc1 allele. GFP-expressing cells were collected by fluorescenceactivated cell sorting, and real-time RT-PCR analysis demonstrated loss of Psmc1 mRNA in mutant MEFs from $2 \mathrm{~d}$ after transduction (Table 1). Western analysis at $4 \mathrm{~d}$ after transduction confirmed that Cre-mediated recombination of floxed Psmc1 resulted in loss of PSMC1 protein (supplemental Fig. $1 E$, available at www.jneurosci.org as supplemental material).

\section{PSMC1 is necessary for assembly and activity of the $26 \mathrm{~S}$ proteasome}

Control and $P s m c 1^{\mathrm{fl} / \mathrm{fl}} ; C a M K I I \alpha$-Cre (mutant) cortical tissue was subjected to glycerol density gradient centrifugation and fractions were assayed for chymotrypsin-like activity. The characteristic bimodal profile of $20 \mathrm{~S}$ and $26 \mathrm{~S}$ proteasome activity was evident in controls, with the $26 \mathrm{~S}$ complex contributing the majority of proteasomal activity (Fig. $1 A$ ). Western analyses confirmed proteasome sedimentation positions (supplemental Fig. 2, available at www.jneurosci.org as supplemental material). At 2 weeks of age, the proteasomal distribution was comparable in control 

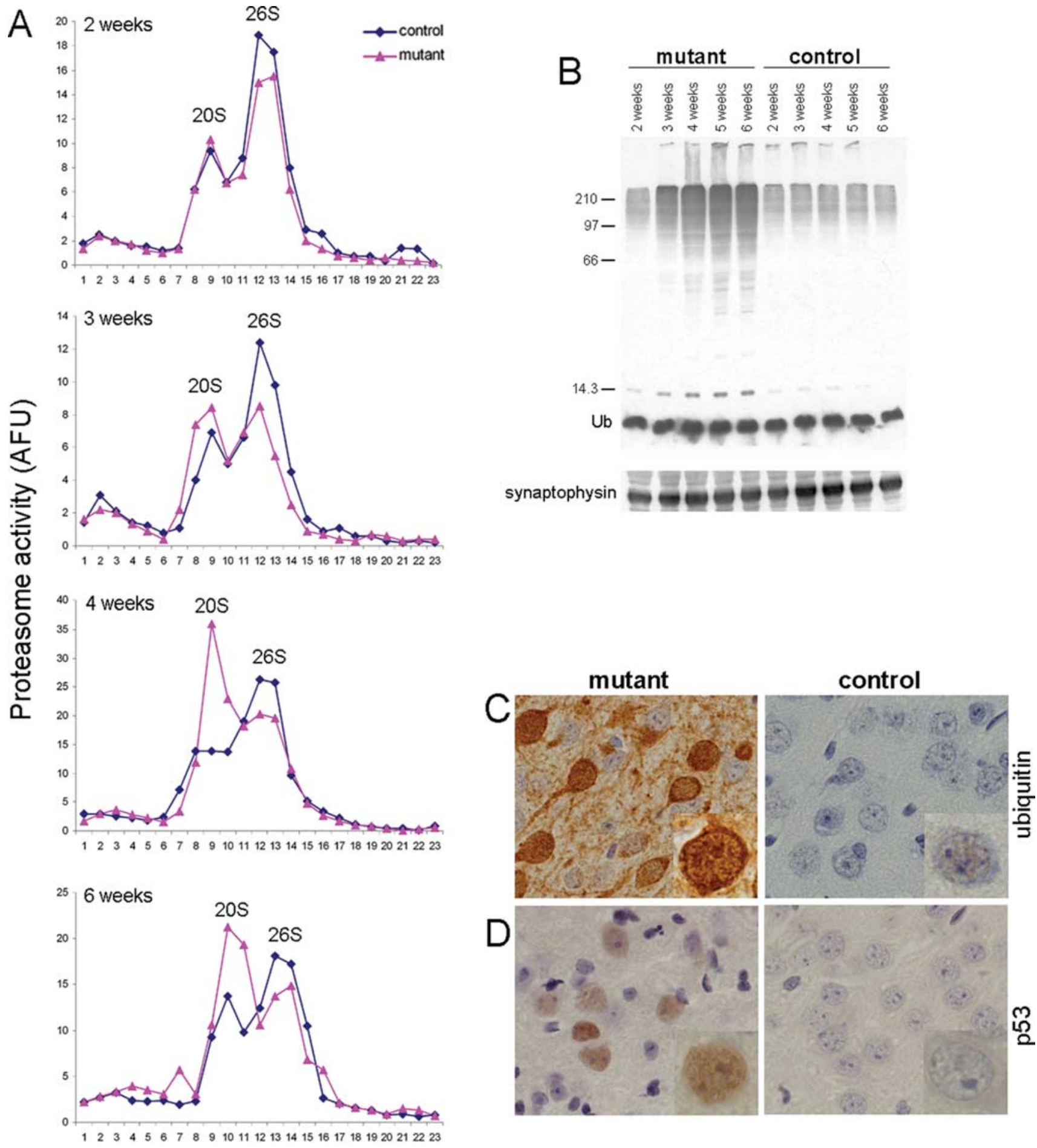

Fraction number

Figure 1. Ablation of Psmc1 causes 265 proteasome depletion. A, Representative proteasome profiles from cortex of 2-, 3-, 4-, and 6-week-old control and Psmc ${ }^{\text {fl/flf; }}$; CaMKIIl $\alpha$-Cre (mutant) mice after glycerol density gradient centrifugation. Fractions 1 and 23 correspond to the top (10\%) and bottom (40\%) of the gradient, respectively. 205 and 265 proteasomal distribution was revealed by succinyl-Leu-Leu-Val-Tyr-7-amido-4-methylcoumarin hydrolysis activity of gradient fractions. Individual experiments at different ages are not directly comparable because of, for example, the amount of protein loaded and slight variability in fraction collection. AFU, Arbitrary fluorescent unit. B, Accumulation of polyubiquitinated proteins, but not free ubiquitin (Ub), in the Psmc ${ }^{f l / f l}$; CaMKII $\alpha$-Cre (mutant) cortex with increasing age, shown by Western analysis of cortex homogenates with an anti-ubiquitin antibody. Anti-synaptophysin was used as a loading control. C, $\mathbf{D}$, Immunohistological staining of cortex sections from 6-week-old control and Psmc $1^{\mathrm{fl} / f l} ;$;aMKII $\alpha$-Cre (mutant) mice using anti-ubiquitin (C) and anti-p53 (D) antibodies (40X). Highermagnification images are inset into the representative sections.

and mutant cortex (Fig. 1A). In 3-week-old mice, less $26 \mathrm{~S}$ complexes were observed in the mutant compared with the control, with an increase in lower molecular weight fractions corresponding to $20 \mathrm{~S}$ (Fig. $1 \mathrm{~A}$ ). The altered profile of proteasome activity in the $P s m c 1^{\mathrm{f} / \mathrm{fl}} ; \mathrm{CaMKII} \alpha$-Cre cortex is clear at 4 and 6 weeks (Fig. $1 A$ ), at which $20 \mathrm{~S}$ is the predominant complex. Because CaMKII $\alpha$-Cre activity is upregulated in mutant cortical neurons during postnatal weeks 2 and 3, the data indicate that ensuing 

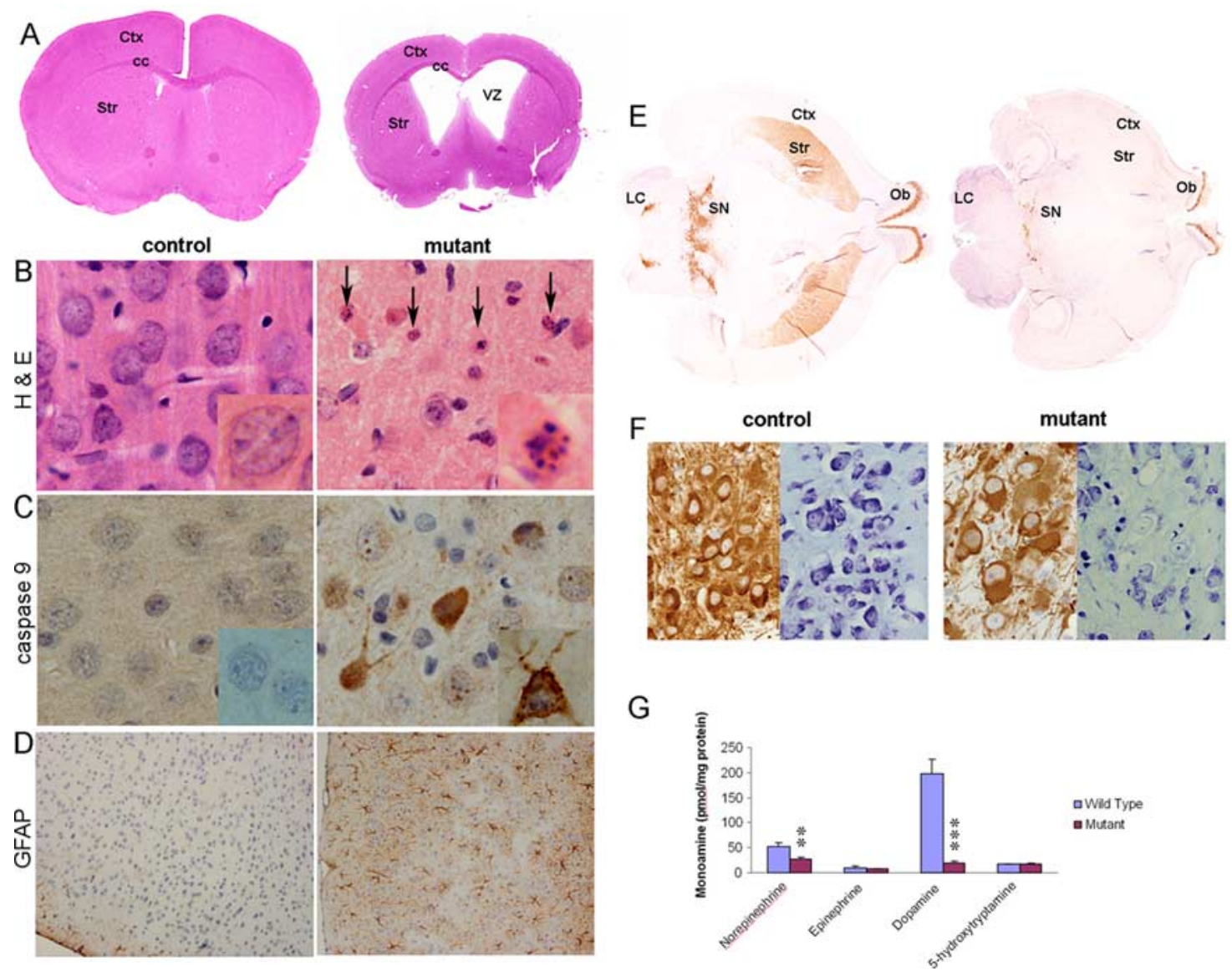

Figure 2. 265 proteasomal dysfunction causes neurodegeneration. $\boldsymbol{A}-\boldsymbol{D}$, Histological examination of coronal sections from control and Psmc $1^{\mathrm{fl} / \mathrm{fl} ;} ;$ CaMKIl $\alpha$-Cre (mutant) mouse brains at 8 weeks of age. $\boldsymbol{A}$, Hematoxylin and eosin (H\&E)-stained whole-brain sections, shown at higher magnification in $\boldsymbol{B}(40 \times)$. The arrows point to pyknotic and fragmented nuclei in the mutant cortex. Immunohistochemistry with antibodies to cleaved caspase $9(40 \times)(\boldsymbol{C})$ and GFAP $(10 \times)(\boldsymbol{D})$ in cortex sections. Representative individual neurons are magnified and shown in the inset of appropriate figures. $\boldsymbol{E}$, TH-stained horizontal sections of whole brain at the level of the nigrostriatal pathway from Psmc $1^{\mathrm{fl} / \mathrm{fl}} ; \mathrm{TH}^{\mathrm{Cre}}$ (mutant) and control mice. $\boldsymbol{F}$, TH and Nissl staining of sequential sections from the substantia nigra of control and $P_{S m C} 1^{\mathrm{flff}} ; T_{H}{ }^{\mathrm{Cre}}$ (mutant) mice $(20 \times)$. G, Catecholamine and indolamine levels measured by HPLC with electrochemical detection in the striatum of Psm ${ }^{\mathrm{fl} / \mathrm{fl}} ; \mathrm{TH}^{\mathrm{Cre}}$ (mutant) and control mice. Graph represents mean \pm SEM (controls, $n=5$; mutants, $n=7$ ). ${ }^{* *} p<0.01$ and ${ }^{* * *} p<0.001$ from control mice by unpaired Student's t test. Ctx, Cerebral cortex; cc, corpus callosum; Str, striatum; VZ, ventricular zone; $0 \mathrm{~b}$, olfactory bulb; $\mathrm{SN}$, substantia nigra; LC, locus ceruleus.

progressive depletion of PMSC1 disrupts $26 \mathrm{~S}$ formation. Residual $26 \mathrm{~S}$ proteasome activity is present because of nontargeted neurons and gliosis (Fig. 2D). This is the first report of mammalian $26 \mathrm{~S}$ proteasome disruption in vivo (cf. Wójcik and DeMartino, 2002; Koulich et al., 2008); the gradual change in proteasomes between 2 and 4 weeks indicates a relatively long half-life associated with the $26 \mathrm{~S}$ proteasome. As intended, $20 \mathrm{~S}$ proteolytic core formation, and therefore ubiquitin-independent proteasomal degradation, was not affected in our model.

$26 \mathrm{~S}$ proteasomal dysfunction was confirmed by accumulation of high molecular weight polyubiquitinated proteins with increasing age (Fig. $1 B$ ) and significantly increased ubiquitin immunostaining in affected neurons (Fig. 1C) in the $P s m c 1^{\mathrm{f} / \mathrm{fl}}$; CaMKII $\alpha$-Cre cortex (mutant) compared with control. The level of p53, which undergoes robust ubiquitin-dependent degradation, was also significantly elevated (Fig. 1D).

Increased $20 \mathrm{~S}$ proteasome activity in the $P s m c 1^{\mathrm{f} / \mathrm{fl}} ; C a M K I I \alpha-$ Cre (mutant) cortex with age appears to be higher than would be expected for a direct shift of the $20 \mathrm{~S}$ activity that would normally be associated with $26 \mathrm{~S}$ complexes (Fig. 1A). This may be explained by upregulation of proteasomal gene expression and biogenesis of active $20 \mathrm{~S}$ complexes in response to $26 \mathrm{~S}$ proteasome impairment (Wójcik and DeMartino, 2002; Meiners et al., 2003; Lundgren et al., 2005; Fuchs et al., 2008). In our MEF model, a significant increase in representative proteasome subunit mRNAs was observed $3 \mathrm{~d}$ after transduction (Table 1 ). This is most likely attributable to transcriptional activation (Meiners et al., 2003). Together with the observations in vivo, these results suggest that proteasome subunits are upregulated in an attempt to maintain proteasomal homeostasis in the absence of PSMC1.

$P s m c 1^{\mathrm{f} / / \mathrm{fl}} ; C a M K I I \alpha-C r e$ and $P s m c 1^{\mathrm{f} / / \mathrm{f}} ; T_{H}^{\mathrm{Cre}}$ offspring are viable and indistinguishable from their littermates at birth. Subtle growth retardation was observed in $P s m c 1^{\mathrm{fl} / \mathrm{fl}} ; \mathrm{CaMKII \alpha} \alpha$-Cre mice from 5 weeks of age (supplemental Fig. $3 A$, available at www. jneurosci.org as supplemental material), and they die when aged 3-4 months, when they lack interest in locating food. These mice were significantly more anxious in open-field analysis and displayed obvious spatial learning deficits in the Morris water maze task at 6 and 8 weeks, respectively, suggesting 26S proteasomal function is essential for normal neurological function in mice (supplemental Fig. $3 B, C$, available at www.jneurosci.org as supplemental material). $P s m c 1^{\mathrm{fl} / \mathrm{fl}} ; T H^{\mathrm{Cre}}$ mice became progressively runty from approximately day 14 and die before postnatal day 28 (see below).

\section{$26 \mathrm{~S}$ proteasomal depletion causes neurodegeneration}

Gross histological analysis of brains from control and $P s m c 1^{\mathrm{f} / \mathrm{fl}}$; CaMKII $\alpha$-Cre (mutant) mice revealed significant progressive at- 
rophy of the forebrain, exemplified by reduced cortical thickness and expansion of the ventricular cavities (Fig. 2A; supplemental Fig. 4, available at www. jneurosci.org as supplemental material). At 2 weeks of age, there were no degenerative changes evident in the $P s m c 1^{\mathrm{fl} / \mathrm{fl}}$; CaMKII $\alpha$-Cre forebrain (supplemental Fig. $4 A$, available at www.jneurosci.org as supplemental material). However, we observed numerous pyknotic nuclei with hematoxylin and eosin staining at 4 weeks of age, which increased in 6-week-old mice, preceding the extensive neuronal loss by 8 weeks (Fig. $2 A, B$; supplemental Fig. $4 B$, available at www.jneurosci.org as supplemental material). Pyknotic nuclei suggested an apoptotic mechanism of neurodegeneration. This was confirmed by upregulation of the apoptosis signaling molecule, cleaved caspase-9 (Fig. 2C). Decreased Bcl-2 expression was observed in the MEF model (Table 1). It remains possible that alternative death mechanisms contribute to degeneration of these neurons. Immunohistochemical staining with GFAP demonstrated extensive astrocytic gliosis accompanied the neuronal loss (Fig. 2D). Neurodegeneration was evident in other CaMKII $\alpha$-expressing regions of the $P s m c 1^{\mathrm{fl} / \mathrm{fl}}$;CaMKII $\alpha$-Cre brain, including the hippocampus, striatum, and amygdala (data not shown). We conclude that $26 \mathrm{~S}$ proteasomal depletion directly causes neurodegeneration.

In $P s m c 1^{\mathrm{fl} / \mathrm{fl}} ; T H^{\mathrm{Cre}}$ mice, $26 \mathrm{~S}$ proteasomal dysfunction in dopaminergic neurons of the nigrostriatal pathway led to progres-

sive degeneration and consequent loss of neuronal projections to the basal ganglia, as evidenced by $\mathrm{TH}$ immunostaining up to 3 weeks of age (Fig. 2 E) (data not shown). TH and Nissl staining of adjacent sections revealed this was neurodegeneration and not downregulation of TH expression (Fig. $2 F$ ). In neurochemical support of the observations, significant catecholaminergic deficits were evident in the $P s m c 1^{\mathrm{fl} / \mathrm{fl}} ; T H^{\mathrm{Cre}}$ brain, including decreases in dopamine and norepinephrine in the striatum (Fig. $2 G$ ) and hypothalamus, and a decrease in norepinephrine in the hippocampus and brainstem (data not shown). Figure 3 emphasizes the ubiquitin accumulation in surviving neurons of the substantia nigra and extensive gliosis as a result of the neuronal damage. $26 \mathrm{~S}$ proteasomal depletion in all catecholaminergic neurons of the $P s m c 1^{\mathrm{fl} / \mathrm{fl}} ; T H^{\mathrm{Cre}}$ mice causes autonomic dysfunction (data not shown), explaining premature death.

\section{Intraneuronal inclusions in $26 \mathrm{~S}$ proteasome-depleted neurons}

In parallel, we examined protein aggregation in the mouse brains using diagnostic antibodies for major human neurodegenerative diseases. Diffuse accumulation of ubiquitinated proteins was evident in a few forebrain neurons in $\mathrm{Ps}_{\mathrm{A}} \mathrm{I}^{\mathrm{fl} / \mathrm{fl}} ; \mathrm{CaMKII \alpha}$-Cre mice at 2 weeks, but no other differences were observed at this age (supplemental Fig. 4, available at www.jneurosci.org as supplemental material). By 4 weeks of age, coincident with progressive
$26 \mathrm{~S}$ proteasomal impairment, there was significant ubiquitin pathology. However, we also observed numerous eosinophilic intraneuronal paranuclear inclusions, containing ubiquitin, $\alpha$-synuclein, and p62, similar to Lewy bodies (LBs) seen in the brains of patients with dementia with Lewy bodies (DLB) (Fig. $4 A-D$; supplemental Fig. 4, available at www.jneurosci.org as supplemental material). $P s m c 1^{\mathrm{fl} / \mathrm{fl}} ; T H^{\text {Cre }}$ nigral neurons also demonstrated a similar phenomenon, resembling Lewy bodies of PD (supplemental Fig. 5, available at www.jneurosci.org as supplemental material). Although $\alpha$-synuclein-immunoreactive neurites were not found in the mice, in contrast to human disease, some of these inclusions stained with $\gamma$-tubulin, PGP 9.5, $\alpha \mathrm{B}$ crystallin, and neurofilament protein, supporting their similarity to Lewy bodies (supplemental Fig. 5, available at www. jneurosci.org as supplemental material) (data not shown) (Shults, 2006). No A $\beta$ ( $\beta$-amyloid)-containing amyloid or tau protein deposits were evident on immunostaining (data not shown). Therefore, Lewy-like inclusion formation and neuronal loss are independent of amyloid formation in this model.

Electron microscopy of Lewy-like inclusions revealed spherical structures with a lamellar appearance (Fig. $4 E$; supplemental Fig. 6, available at www.jneurosci.org as supplemental material). Numerous mitochondria, fine filaments, and granular material were evident in the central region, surrounded by a zone of clear vesicular and membranous material, as well as double- 

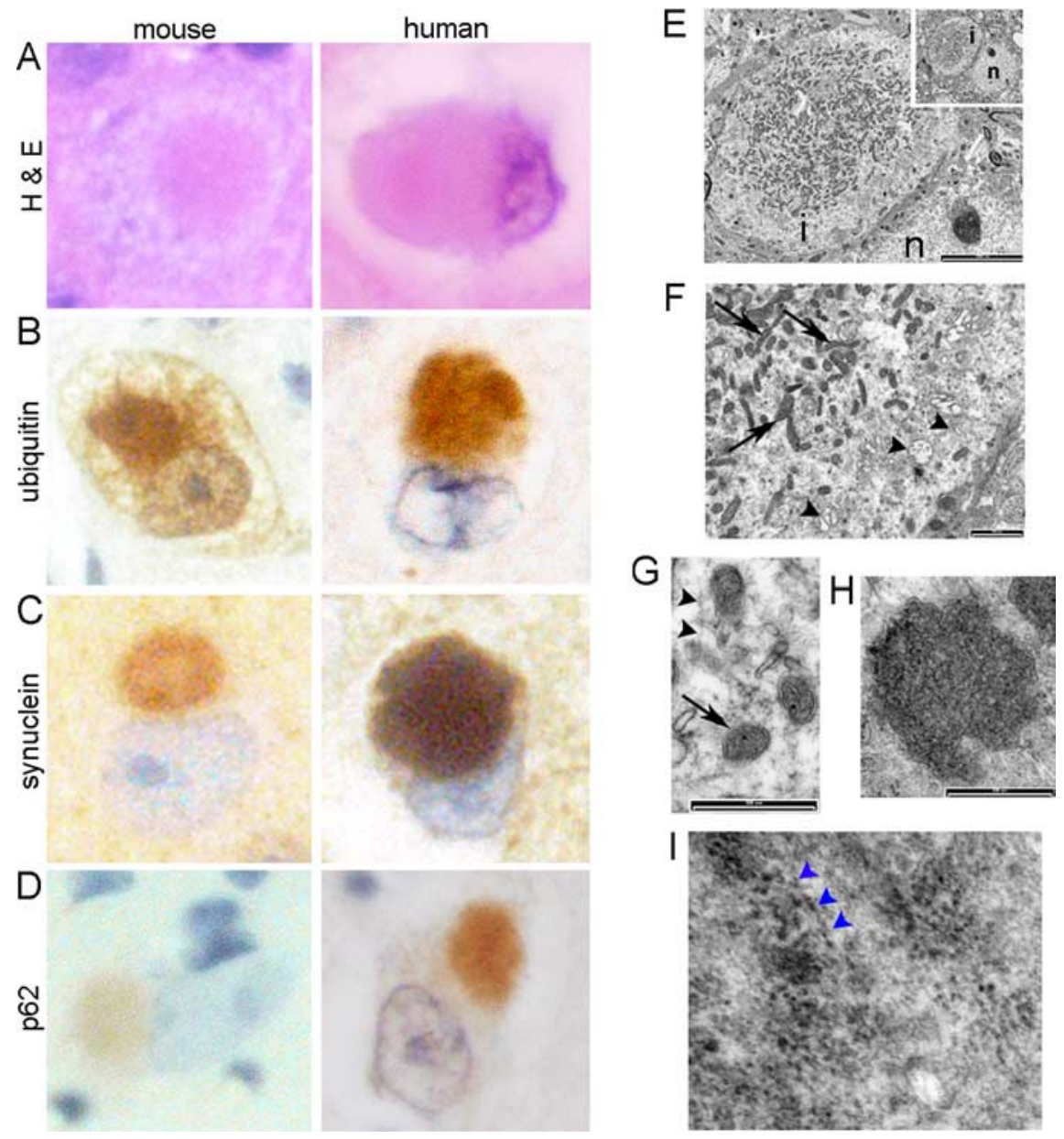

Figure 4. Lewy-like intraneuronal inclusions in 265 proteasome-depleted neurons. $\boldsymbol{A}-\boldsymbol{D}$, Representative Lewy-like inclusions in mouse cortical neurons at 6 weeks of age stained with $H \& E$ and ubiquitin, $\alpha$-synuclein, and $p 62$ antibodies, directly compared with Lewy bodies from the brains of patients with dementia with Lewy bodies $(100 \times)$. No inclusions were observed in the control mouse brains (data not shown). $\boldsymbol{E}-\boldsymbol{I}$, Ultrastructure of mouse Lewy-like inclusions by EM. The paranuclear inclusion ( $\boldsymbol{E}$; inset; $n$, nucleus; i, inclusion) contains mitochondria ( $\boldsymbol{F}, \boldsymbol{G}$, arrows), a background matrix of fine filaments ( $\boldsymbol{G}$, arrowheads) and granular material, with peripheral membrane-bound vesicles ( $\boldsymbol{F}$, arrowheads), including double-membraned autophagosome-like dense bodies $(\boldsymbol{H})$. $\boldsymbol{I}$, Filamentous $\alpha$-synuclein is associated with $10 \mathrm{~nm}$ gold particles by immunoelectron microscopy. The arrowheads point to particles aligned along distinct filaments. Scale bars: $\boldsymbol{E}, 5000 \mathrm{~nm} ; \boldsymbol{E}, 1000 \mathrm{~nm} ; \boldsymbol{G}, \boldsymbol{H}, 500 \mathrm{~nm}$.

membraned autophagolysomes, suggesting the autophagic processes followed $26 \mathrm{~S}$ proteasomal dysfunction (Fig. $4 \mathrm{E}-\mathrm{H}$; supplemental Fig. 6, available at www.jneurosci.org as supplemental material). Immunogold labeling with anti- $\alpha$-synuclein revealed some filaments with $10 \mathrm{~nm}$ gold particles in the central region (Fig. 4I). In support of this observation, a subset of inclusions stained with the amyloid-binding dye thioflavin S (supplemental Fig. 6, available at www.jneurosci.org as supplemental material).

\section{Mitochondrial involvement in inclusion body formation}

The pattern of $\alpha$-synuclein aggregate in our model, containing mitochondria, has been recognized in human disease and is considered to be an early form of Lewy body (Gai et al., 2000). The paucity of literature on mitochondria in human disease led us to substantiate our findings by EM analysis of substantia nigra from PD patients. This revealed the presence of mitochondria in pale bodies, an $\alpha$-synuclein-containing inclusion thought to be an early form of nigral Lewy body (Fig. 5A). In the example shown, the larger mitochondria-containing $\mathrm{PB}$ is adjacent to a smaller $\mathrm{LB}$, which is devoid of mitochondria. Mitochondria-rich inclusions were further investigated using cox IV immunostaining. cox IV was seen in a proportion of human cortical Lewy bodies as well as in nigral pale bodies, but was absent from classical dense core Lewy bodies (Fig. 5B-D). Therefore, the mouse model probably represents filamentous $\alpha$-synuclein aggregates containing mitochondria as "earlystage" intraneuronal inclusions. The inclusions do not progress to reveal Lewy bodies with a dense core and lamellar pattern as in human disease. The abundance of mitochondria in mouse Lewy-like bodies after $26 \mathrm{~S}$ proteasomal impairment suggests that mitochondria might play a direct role in Lewy body formation and/or function.

\section{Discussion}

We report a conditional knock-out mouse harboring $26 \mathrm{~S}$ proteasomal dysfunction in neurons, enabling a definitive link between ubiquitinated protein degradation by the $26 \mathrm{~S}$ proteasome and neuronal pathology to be established. Impaired 26S proteasomal function causes neurodegeneration and intraneuronal inclusion body formation, reflecting early forms of human Lewy bodies described as homogeneous Lewy bodies (Gai et al., 2000) or pale bodies (Dale et al., 1992). The intraneuronal inclusions in our mouse model are different from those seen in PD or DLB because the classical concentric Lewy body does not form. The reasons for this are currently unknown. It is possible that neurodegeneration proceeds before the time that would be necessary to form a latestage concentric Lewy body. This is most likely a consequence of the genetic approach taken in this model, which rapidly ablates $26 \mathrm{~S}$ proteasomal function. In contrast, progressive proteasomal inhibition with aging most likely occurs in human disease. Alternatively, there may be intrinsic differences in the pathophysiology between the mouse model and human disease.

Based on mutational studies of the ATPase subunits in the base of the 19S RP using yeast proteasomes as a model, we chose to inactivate Psmc1 (Rpt2/S4) to generate a novel mouse model of specifically 26 S proteasomal dysfunction (Seeger et al., 1996; Rubin et al., 1998; Köhler et al., 2001). Because the six base ATPases are functionally nonredundant, deletion of PSMC1 would prevent hexameric ring biogenesis in the base of the 19S RP and coassembly with the 20S CP. PSMC1 also has a unique role in proteolysis activity of the 20S core. Using glycerol gradient analysis, we demonstrate here in higher eukaryotes that ablation of PSMC1 in mouse neurons disrupts $26 \mathrm{~S}$ proteasome formation, but does not affect the 20S CP. Therefore, in contrast to the use of $20 \mathrm{~S}$ proteasome inhibitors in models of $\mathrm{PD}$, which do not differentiate between ubiquitin-dependent and ubiquitinindependent degradation or neurons and glia, the neuropathological changes evident in our mouse model are linked to neuronal $26 \mathrm{~S}$ proteasomal dysfunction. This model also reveals the importance of the $26 \mathrm{~S}$ proteasome versus the $20 \mathrm{~S}$ proteolytic $\mathrm{CP}$ 
A

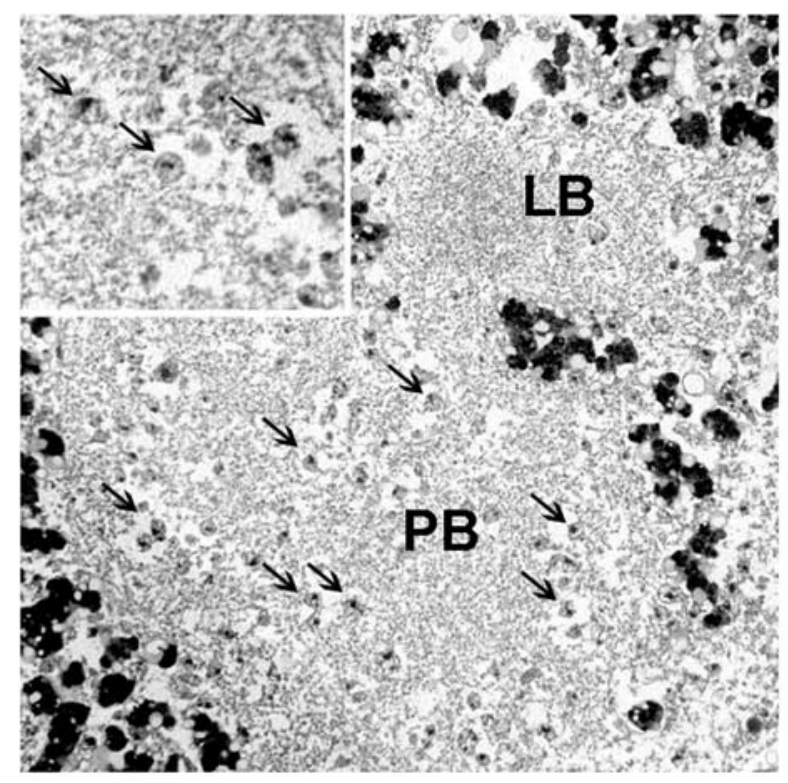

$\mathrm{B}$
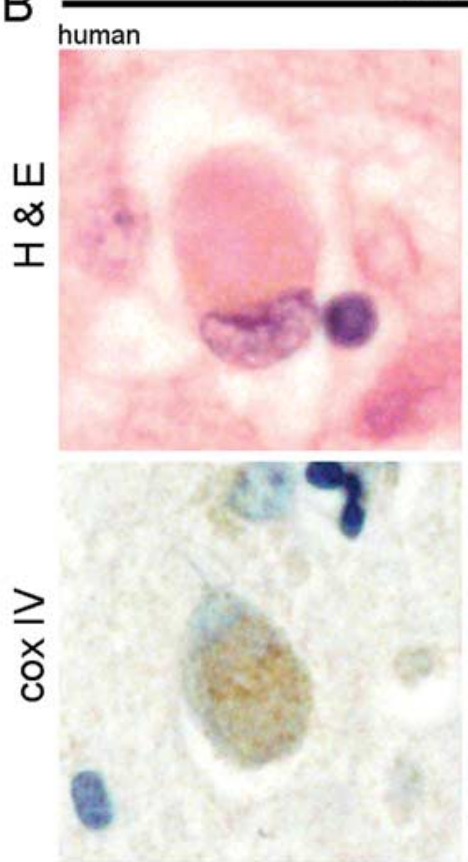

cortical

\section{mouse}
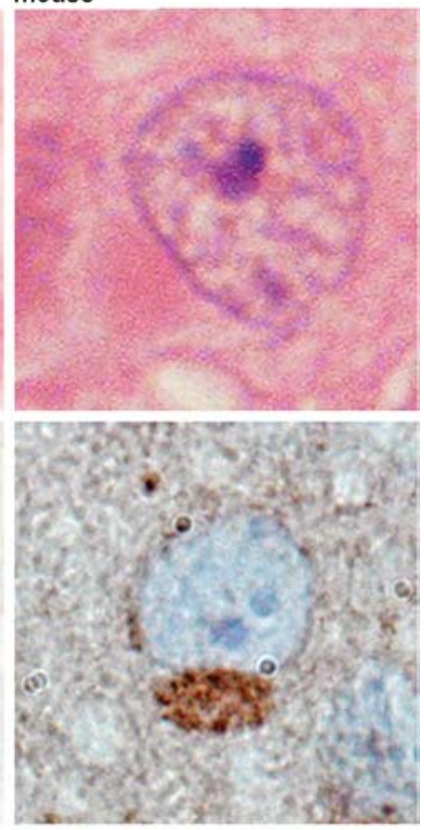

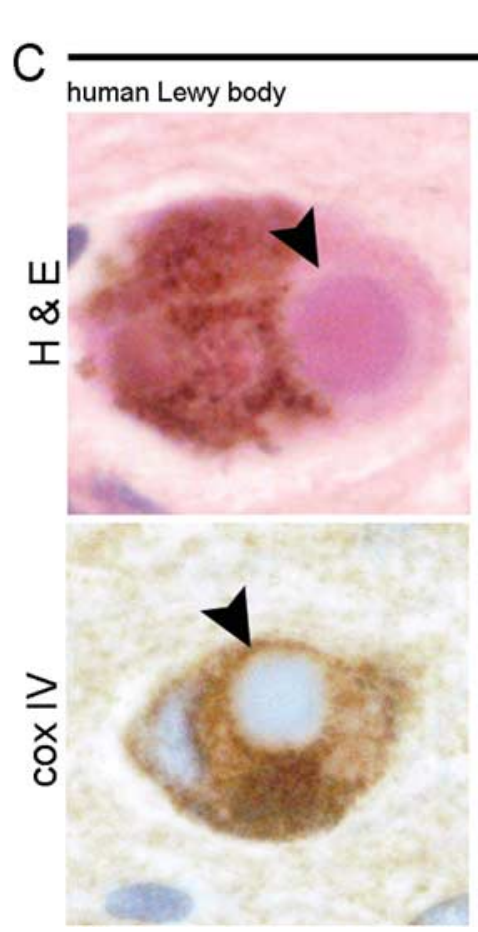

nigral
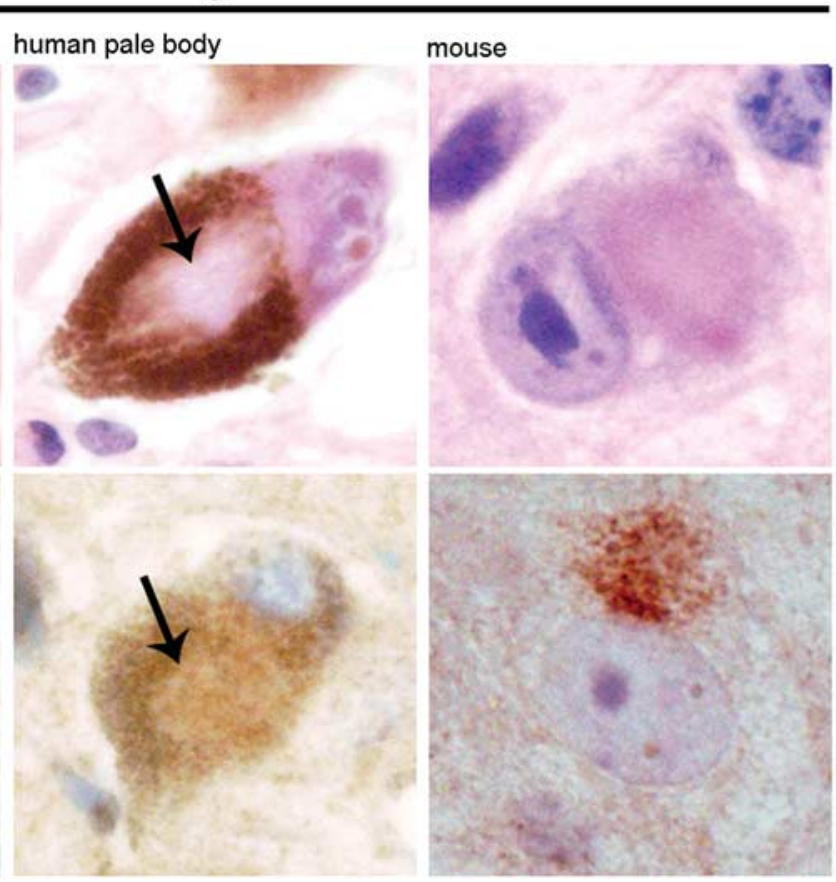

$\mathrm{D}$

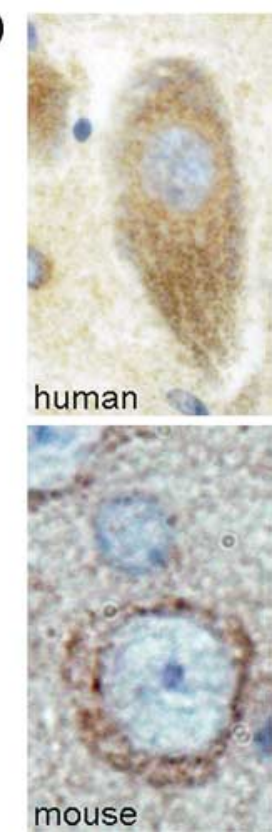

Figure 5. Mitochondria in human and mouse Lewy bodies. $A$, EM showing mitochondria (arrows) among filamentous material in a human nigral PB, which is adjacent to a classical $L B$ that is devoid of mitochondria. Enlarged view of mitochondria within the pale body is shown in the inset. $\boldsymbol{B}$, C, Shown is H\&E and cox IV immunostaining of cortical Lewy bodies ( $\boldsymbol{B}$ ) and nigral Lewy and pale

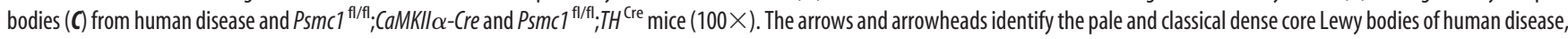
respectively. $D$, The normal pattern of cox IV in human and mouse neurons $(100 \times)$. The heavy brown pigment in H\&E human nigral neurons is neuromelanin.

in neuronal homeostasis. The $20 \mathrm{~S}$ core is unable to maintain neuronal survival in the absence of PSMC1. It is still possible that a decrease in 20 S proteolytic activity of the proteasome occurs with aging in neurodegenerative disease. Importantly, this work demonstrates that the pathological consequences of a decrease in $20 \mathrm{~S} \mathrm{CP}$ activity are linked to the ubiquitin-mediated degradation pathway.

This model differs significantly from current models of neu- rodegenerative disease, in which neuronal loss is minimal and generally not seen in regions linked to disease (McGowan et al., 2006; Melrose et al., 2006) (e.g., the substantia nigra in $\alpha$-synuclein-expressing transgenic mice). Neurodegeneration may be an expected consequence of PSMC1 and thence 26S proteasomal depletion in mouse neurons. The early Schizosaccharomyces pombe and Saccharomyces cerevisiae models of proteasomal dysfunction, with mutation of the homologous ATPase $m t s 2$ or 
rpt2, respectively, reflect the observations in our mouse model. Lack of the functional ATPase caused accumulation of ubiquitinated proteins and growth defects (Gordon et al., 1993; Seeger et al., 1996; Rubin et al., 1998). More recently, as anticipated, proteasome-dependent activities are being revealed as fundamental in the nervous system (Yi and Ehlers, 2007). Although a buildup of polyubiquitinated proteins and degeneration may be obvious effects of disrupted neuronal proteasomal homeostasis in this model, previous work did not suggest that intracellular paranuclear inclusion body formation would occur, resembling early-stage Lewy bodies seen in human disease. This could be explained by inherent differences in mechanisms between higher and lower eukaryotes. The formation of inclusion bodies with some of the currently accepted features of Lewy bodies (Shults, 2006) suggests $26 \mathrm{~S}$ proteasome dysfunction is associated with a cascade of specific neuropathological changes that occur in disease progression.

Much research into the synucleinopathies, particularly Parkinson's disease, focuses on mechanisms involving $\alpha$-synuclein, but more recently mitochondrial involvement in the biology of Lewy body disorders has been recognized. We demonstrate both $\alpha$-synuclein and mitochondria are linked to neuropathological changes after proteasomal dysfunction, which itself is consistently associated with disease (Gandhi and Wood, 2005). Although proteasomal dysfunction may prevent the degradation of $\alpha$-synuclein and other proteins, which then accumulate passively in paranuclear aggresomes (Lewy-like bodies), another interpretation is that $\alpha$-synuclein may be an essential protein involved in the biogenesis of Lewy bodies and its accumulation is an active event. This is supported by the disproportionate and early accumulation of $\alpha$-synuclein in inclusion bodies after $26 \mathrm{~S}$ proteasomal dysfunction in neurons; $\alpha$-synuclein is not recognized as a protein that has a high turnover mediated by the UPS, and has been reported to undergo ubiquitin-independent degradation (Tofaris et al., 2001).

Mitochondria are a striking component of the inclusion bodies in mouse neurons and we show current evidence for mitochondria in some human cortical and nigral early-stage Lewy bodies. Mitochondria have also been noted as a component of Lewy-like aggresomes induced by proteasome inhibition (AbouSleiman et al., 2006). The precise role of mitochondria in neurodegenerative disease remains uncertain. Evidence for mitochondrial dysfunction is provided by mutations in genes that are associated with mitochondria in familial PD [e.g., mitochondrial kinase PINK (PTEN-induced kinase 1) and Parkin (Valente et al., 2004; Poole et al., 2008)], and features of PD are caused by mitochondrial toxins (Bové et al., 2005). The observations made in the mouse models and reexamination of human pathology convinces us to propose a hypothesis that suggests that mitochondria are a key component of an early phase in the biogenesis of the Lewy body.

Another mechanistic possibility for the findings described here that will need additional investigation is that the roles of the $26 \mathrm{~S}$ proteasome, 19S RP, and 20S catalytic core in gene expression (Gonzalez et al., 2002; Sikder et al., 2006) may be affected by the loss of PSMC1. Progranulin mutations result in neuronal cytoplasmic inclusions containing TDP43, which is normally involved in transcription and exon skipping and may cause neurodegeneration by errors in gene expression (Eriksen and Mackenzie, 2008).

The known options for the isolation and/or degradation of unwanted proteins in the absence of the UPS are the formation of aggresomes (Johnston et al., 1998) and macroautophagy. The neuroprotective function of macroautophagy has become an interesting focus in neurodegenerative disease, exemplified in Huntington's disease (Menzies et al., 2006; Mizushima et al., 2008), as well as in animal models (Hara et al., 2006; Komatsu et al., 2006). Whether this alternative nonselective proteolytic pathway plays a role during dysfunction of the UPS is still unclear. Proteasome function was found to be normal in autophagydeficient brain (Komatsu et al., 2006). Preliminary experiments in 26S proteasome-ablated MEFs did not show significant upregulation of autophagic genes (Table 1), but in vivo EM analysis revealed double-membraned autophagolysomes.

This is the first mouse model that permits investigation into $26 \mathrm{~S}$ proteasomal dysfunction in neurons. We demonstrate that impairment of neuronal 26S proteasomes in the neocortex or substantia nigra causes florid neurodegeneration and Lewy-like inclusion body formation, resembling pathophysiology evident in the brains of patients with DLB and PD, respectively. The models described here provide unparalleled novel platforms in which to investigate and exploit therapeutic approaches to prevent neurodegeneration in the brain.

\section{References}

Abou-Sleiman PM, Muqit MM, Wood NW (2006) Expanding insights of mitochondrial dysfunction in Parkinson's disease. Nat Rev Neurosci 7:207-219.

Bayer SA, Wills KV, Triarhou LC, Ghetti B (1995) Time of neuron origin and gradients of neurogenesis in midbrain dopaminergic neurons in the mouse. Exp Brain Res 105:191-199.

Bennett EJ, Shaler TA, Woodman B, Ryu KY, Zaitseva TS, Becker CH, Bates GP, Schulman H, Kopito RR (2007) Global changes to the ubiquitin system in Huntington's disease. Nature 448:704-708.

Bové J, Prou D, Perier C, Przedborski S (2005) Toxin-induced models of Parkinson's disease. NeuroRx 2:484-494.

Burgin KE, Waxham MN, Rickling S, Westgate SA, Mobley WC, Kelly PT (1990) In situ hybridization histochemistry of $\mathrm{Ca}^{2+} /$ calmodulindependent protein kinase in developing rat brain. J Neurosci 10:1788-1798.

Dale GE, Probst A, Luthert P, Martin J, Anderton BH, Leigh PN (1992) Relationships between Lewy bodies and pale bodies in Parkinson's disease. Acta Neuropathol 83:525-529.

Demartino GN, Gillette TG (2007) Proteasomes: machines for all reasons. Cell 129:659-662.

Elsasser S, Gali RR, Schwickart M, Larsen CN, Leggett DS, Müller B, Feng MT, Tübing F, Dittmar GA, Finley D (2002) Proteasome subunit Rpn1 binds ubiquitin-like protein domains. Nat Cell Biol 4:725-730.

Eriksen JL, Mackenzie IR (2008) Progranulin: normal function and role in neurodegeneration. J Neurochem 104:287-297.

Fuchs D, Berges C, Opelz G, Daniel V, Naujokat C (2008) Increased expression and altered subunit composition of proteasomes induced by continuous proteasome inhibition establish apoptosis resistance and hyperproliferation of Burkitt lymphoma cells. J Cell Biochem 103:270-283.

Gai WP, Yuan HX, Li XQ, Power JT, Blumbergs PC, Jensen PH (2000) In situ and in vitro study of colocalization and segregation of alphasynuclein, ubiquitin, and lipids in Lewy bodies. Exp Neurol 166:324-333.

Gandhi S, Wood NW (2005) Molecular pathogenesis of Parkinson's disease. Hum Mol Genet 14:2749-2755.

Giasson BI, Lee VM (2001) Parkin and the molecular pathways of parkinson's disease. Neuron 31:885-888.

Glickman MH, Ciechanover A (2002) The ubiquitin-proteasome proteolytic pathway: destruction for the sake of construction. Physiol Rev 82:373-428.

Gonzalez F, Delahodde A, Kodadek T, Johnston SA (2002) Recruitment of a $19 \mathrm{~S}$ proteasome subcomplex to an activated promoter. Science 296:548-550.

Gordon C, McGurk G, Dillon P, Rosen C, Hastie ND (1993) Defective mitosis due to a mutation in the gene for a fission yeast $26 \mathrm{~S}$ protease subunit. Nature 366:355-357.

Groll M, Huber R (2003) Substrate access and processing by the 20S proteasome core particle. Int J Biochem Cell Biol 35:606-616. 
Groll M, Ditzel L, Löwe J, Stock D, Bochtler M, Bartunik HD, Huber R (1997) Structure of $20 \mathrm{~S}$ proteasome from yeast at $2.4 \AA$ resolution. Nature 386:463-471.

Groll M, Bajorek M, Köhler A, Moroder L, Rubin DM, Huber R, Glickman $\mathrm{MH}$, Finley D (2000) A gated channel into the proteasome core particle. Nat Struct Biol 7:1062-1067.

Hara T, Nakamura K, Matsui M, Yamamoto A, Nakahara Y, SuzukiMigishima R, Yokoyama M, Mishima K, Saito I, Okano H, Mizushima N (2006) Suppression of basal autophagy in neural cells causes neurodegeneration in mice. Nature 441:885-889.

Husnjak K, Elsasser S, Zhang N, Chen X, Randles L, Shi Y, Hofmann K, Walters KJ, Finley D, Dikic I (2008) Proteasome subunit Rpn13 is a novel ubiquitin receptor. Nature 453:481-488.

Johnston JA, Ward CL, Kopito RR (1998) Aggresomes: a cellular response to misfolded proteins. J Cell Biol 143:1883-1898.

Köhler A, Cascio P, Leggett DS, Woo KM, Goldberg AL, Finley D (2001) The axial channel of the proteasome core particle is gated by the Rpt2 ATPase and controls both substrate entry and product release. Mol Cell 7:1143-1152.

Komatsu M, Waguri S, Chiba T, Murata S, Iwata J, Tanida I, Ueno T, Koike M, Uchiyama Y, Kominami E, Tanaka K (2006) Loss of autophagy in the central nervous system causes neurodegeneration in mice. Nature 441:880-884.

Kordower JH, Kanaan NM, Chu Y, Suresh Babu R, Stansell J 3rd, Terpstra BT, Sortwell CE, Steece-Collier K, Collier TJ (2006) Failure of proteasome inhibitor administration to provide a model of Parkinson's disease in rats and monkeys. Ann Neurol 60:264-268.

Koulich E, Li X, Demartino GN (2008) Relative structural and functional roles of multiple deubiquitylating proteins associated with mammalian 26S proteasome. Mol Biol Cell 19:1072-1082.

Lam YA, Lawson TG, Velayutham M, Zweier JL, Pickart CM (2002) A proteasomal ATPase subunit recognises the polyubiquitin degradation signal. Nature 416:763-767.

László L, Doherty FJ, Watson A, Self T, Landon M, Lowe J, Mayer RJ (1991) Immunogold localisation of ubiquitin-protein conjugates in primary (azurophilic) granules of polymorphonuclear neutrophils. FEBS Lett 279:175-178.

Lindeberg J, Mattsson R, Ebendal T (2002) Timing the doxycycline yields different patterns of genomic recombination in brain neurons with a new inducible Cre transgene. J Neurosci Res 68:248-253.

Lindeberg J, Usoskin D, Bengtsson H, Gustafsson A, Kylberg A, Söderström S, Ebendal T (2004) Transgenic expression of Cre-recombinase from the tyrosine hydroxylase locus. Genesis 40:67-73.

Lowe J, Blanchard A, Morrell K, Lennox G, Reynolds L, Billett M, Landon M, Mayer RJ (1988) Ubiquitin is a common factor in intermediate filament inclusion bodies of diverse type in man, including those of Parkinson's disease, Pick's disease, and Alzheimer's disease, as well as Rosenthal fibres in cerebellar astrocytomas, cytoplasmic bodies in muscle, and mallory bodies in alcoholic liver disease. J Pathol 155:9-15.

Lundgren J, Masson P, Mirzaei Z, Young P (2005) Identification and characterization of a Drosophila proteasome regulatory network. Mol Cell Biol 25:4662-4675.

Mayford M, Bach ME, Huang YY, Wang L, Hawkins RD, Kandel ER (1996) Control of memory formation through regulated expression of a CaMKII transgene. Science 274:1678-1683.

McGowan E, Eriksen J, Hutton M (2006) A decade of modeling Alzheimer's disease in transgenic mice. Trends Genet 22:281-289.

McNaught KS, Perl DP, Brownell AL, Olanow CW (2004) Systemic exposure to proteasome inhibitors causes a progressive model of Parkinson's disease. Ann Neurol 56:149-162.

Meiners S, Heyken D, Weller A, Ludwig A, Stangl K, Kloetzel PM, Krüger E (2003) Inhibition of proteasome activity induces concerted expression of proteasome genes and de novo formation of mammalian proteasomes. J Biol Chem 278:21517-21525.
Melrose HL, Lincoln SJ, Tyndall GM, Farrer MJ (2006) Parkinson's disease: a rethink of rodent models. Exp Brain Res 173:196-204.

Menzies FM, Ravikumar B, Rubinsztein DC (2006) Protective roles for induction of autophagy in multiple proteinopathies. Autophagy 2:224-225.

Mizushima N, Levine B, Cuervo AM, Klionsky DJ (2008) Autophagy fights disease through cellular self-digestion. Nature 451:1069-1075.

Pickart CM, Cohen RE (2004) Proteasomes and their kin: proteases in the machine age. Nat Rev Mol Cell Biol 5:177-187.

Poole AC, Thomas RE, Andrews LA, McBride HM, Whitworth AJ, Pallanck LJ (2008) The PINK1/Parkin pathway regulates mitochondrial morphology. Proc Natl Acad Sci U S A 105:1638-1643.

Rosenzweig R, Osmulski PA, Gaczynska M, Glickman MH (2008) The central unit within the $19 \mathrm{~S}$ regulatory particle of the proteasome. Nat Struct Mol Biol 15:573-580.

Rubin DM, Glickman MH, Larsen CN, Dhruvakumar S, Finley D (1998) Active site mutants in the six regulatory particle ATPases reveal multiple roles for ATP in the proteasome. EMBO J 17:4909-4919.

Ryu KY, Garza JC, Lu XY, Barsh GS, Kopito RR (2008) Hypothalamic neurodegeneration and adult-onset obesity in mice lacking the Ubb polyubiquitin gene. Proc Natl Acad Sci U S A 105:4016-4021.

Schmidt M, Hanna J, Elsasser S, Finley D (2005) Proteasome-associated proteins: regulation of a proteolytic machine. Biol Chem 386:725-737.

Seeger M, Gordon C, Ferrell K, Dubiel W (1996) Characteristics of 26S proteases from fission yeast mutants, which arrest in mitosis. J Mol Biol 263:423-431.

Shults CW (2006) Lewy bodies. Proc Natl Acad Sci U S A 103:1661-1668.

Sikder D, Johnston SA, Kodadek T (2006) Widespread, but non-identical, association of proteasomal 19 and $20 \mathrm{~S}$ proteins with yeast chromatin. J Biol Chem 281:27346-27355.

Smith DM, Kafri G, Cheng Y, Ng D, Walz T, Goldberg AL (2005) ATP binding to PAN or the 26S ATPases causes association with the $20 \mathrm{~S}$ proteasome, gate opening, and translocation of unfolded proteins. Mol Cell 20:687-698.

Smith DM, Chang SC, Park S, Finley D, Cheng Y, Goldberg AL (2007) Docking of the proteasomal ATPases' carboxyl termini in the 20S proteasome's alpha ring opens the gate for substrate entry. Mol Cell 27:731-744.

Tanahashi N, Murakami Y, Minami Y, Shimbara N, Hendil KB, Tanaka K (2000) Hybrid proteasomes. Induction by interferon-gamma and contribution to ATP-dependent proteolysis. J Biol Chem 275:14336-14345.

Tanaka M, Hadjantonakis AK, Nagy A (2001) Aggregation chimeras. Combining ES cells, diploid and tetraploid embryos. Methods Mol Biol 158:135-154.

Tofaris GK, Layfield R, Spillantini MG (2001) alpha-Synuclein metabolism and aggregation is linked to ubiquitin-independent degradation by the proteasome. FEBS Lett 509:22-26.

Tsien JZ, Chen DF, Gerber D, Tom C, Mercer EH, Anderson DJ, Mayford M, Kandel ER, Tonegawa S (1996) Subregion- and cell type-restricted gene knockout in mouse brain. Cell 87:1317-1326.

Valente EM, Abou-Sleiman PM, Caputo V, Muqit MM, Harvey K, Gispert S, Ali Z, Del Turco D, Bentivoglio AR, Healy DG, Albanese A, Nussbaum R, González-Maldonado R, Deller T, Salvi S, Cortelli P, Gilks WP, Latchman DS, Harvey RJ, Dallapiccola B, et al. (2004) Hereditary early-onset Parkinson's disease caused by mutations in PINK1. Science 304:1158-1160.

Voges D, Zwickl P, Baumeister W (1999) The 26S proteasome: a molecular machine designed for controlled proteolysis. Annu Rev Biochem 68:1015-1068.

Wang J, Wang CE, Orr A, Tydlacka S, Li SH, Li XJ (2008) Impaired ubiquitin-proteasome system activity in the synapses of Huntington's disease mice. J Cell Biol 180:1177-1189.

Welchman RL, Gordon C, Mayer RJ (2005) Ubiquitin and ubiquitin-like proteins as multifunctional signals. Nat Rev Mol Cell Biol 6:599-609.

Wójcik C, DeMartino GN (2002) Analysis of Drosophila 26S proteasome using RNA interference. J Biol Chem 277:6188-6197.

Yi JJ, Ehlers MD (2007) Emerging roles for ubiquitin and protein degradation in neuronal function. Pharmacol Rev 59:14-39. 